\title{
To Work or Not to Work... in a Multicultural Team?
}

\begin{abstract}
The main goal of the article is to present research findings regarding student's attitude to working in a multicultural team (MCT). Research participants of different cultural background completed the research survey. Their willingness to work in MCT was measured together with factors that influence it. These include factors related to both team members and the task structure.

Research findings indicate that the respondents preferred to work in MCT if the task required diversity of cognitive perspectives, e.g. in a situation requiring creative or outof-the-box thinking. In contrast, the strongest preference for working in a single-culture team (SCT) was present in the case of tasks requiring mutual understanding among the team members and like-mindedness. In addition, it was found that the preference to work in SCT or MCT entrusted with a task with specific requirements was also related to the experience in working in such teams declared by the respondents.

Conclusions and recommendations may be utilized to design methods for managerial education and training.
\end{abstract}

\section{Introduction}

The right approach to managing diversity, including cultural diversity, should be based not only on its acceptance but on using it fully [Shen J. et al. 2009, pp. 235-251] in order to increase the efficiency and quality of work of teams and organizations 
[Kellough J.E. and Naff K.C., 2004, pp.62-90]. This approach seems particularly timely now. Globalization understood as a multidimensional process of integration of the world means that work and cooperation in diverse cultural conditions are of fundamental significance for the activities of any organization. Cross-cultural competence, the ability to introduce flexible changes in one's knowledge, attitudes and behaviour as a consequence of openness to cultural differences and the ability to work with others in spite of the identification of these differences [Pillay S. and James R., 2013, pp. 8-9] is cited as one of the ten most important and necessary employee skills in the near future [Davies A., Fidler D. and Gorbis M., 2011, p.9].

This paper refers to the broader issue of education of future managers and entrepreneurs with a view to work in multicultural teams (MCT). The aim of the present study was to investigate whether the preferences of students to work in MCT or single-culture team (SCT) depend on the requirements of the task the team is entrusted with. In addition, it is verified whether such preferences are related to one's past experience in teamwork.

\section{Diverse teams and their effectiveness}

Creation of teams is based on the assumption that they work more efficiently, faster and better than individuals [Church, A.H., 1998, p.45; Katzenbach J.R. and Smith D.K., 2001, p.21; Unsworth K.L. and West M.A., 2003, pp.360-361]. This advantage stems from the possibility of using different cognitive perspectives of their members. An individual can possess superior knowledge, an extraordinary level of skill and a lot of experience, but the proper use of the potential of all members of the team complements and expands its resources above the level available to any person [Katzenbach J.R. and Smith D.K., 2001, pp.55-59; Roberge M.E. and Dick R. 2010, pp.295-308]. It can be concluded that diversity is an inherent and fundamental feature of influencing the functioning and efficiency of teams. Of course, diversity of individuals belonging to a team is not related exclusively to knowledge, skills or experience. Mannix and Neale [2005, p.36] present six categories of such diversity. These are: social category differences (i.a. race, ethnicity, gender, age), differences in knowledge or skills (i.a. education, knowledge, experience), differences in values or beliefs (i.a. cultural background), personality differences (i.a. cognitive style, motivational factors), differences related to organizational status (i.a. length-ofservice) and differences in social and network ties. Bell and Berry [2007, p.21] define diversity as "real or perceived differences among people with regards to race, ethnicity, sex, religion, age, physical and mental ability, sexual orientation, work and family status or weight and appearance that affect their interactions and relationships." In turn, Shore et al. [2009, p.117] mention only six major areas of differences which affect the work of organization and teams: race, gender, age, disability, sexual orientation and national origin. 
Exploring issues related to the work of MCT understood as "a collection of individuals with different cultural backgrounds, who are interdependent in their task, who share responsibility for outcomes, who see themselves and are seen by others as an intact social entity embedded in one or more larger social systems, and who manage their relationships across organization boundaries and beyond" [Tirmizi, S.A., 2008. p.5] seems to be not only interesting but also desirable. In addition to the aforementioned reasons related to globalization, an important factor is the fact that cultural differences can be a source of very strong and rapid categorizations of an antagonist nature (We - They), resulting from the use of stereotypes and prejudices based on simplified cognitive schema [Boski P., 2010, pp. 492-495; Stahl G.K. et al. 2010, pp.439-447].

The results of research indicate that the diversity of the team is conducive to faster and better work [Lawthom, R., 2003, pp. 424-425], innovative and creative solutions [Roberge M.E. and Dick R. 2010, pp.295-308], increased flexibility and ability to adapt to different situations and cooperation [Shen J. et al., 2009, pp. 235-251] and thus to a greater sense of job satisfaction [Pitts, D., 2009, pp. 328338]. Diversity is therefore a factor that, if used properly, can become a source of competitive advantage of a team or an organization. On the other hand, the same diversity may give rise to difficulties in communication within the team and affect the reduced identification and cohesion of its members, which in turn increases the number of stressful situations and conflicts that reduce opportunities for cooperation and adversely affect efficiency [Unsworth K.L. and West M.A., 2003, p. 366; Woehr D.J., Arciniega L.M. and Poling, T.L., 2013, p.109].

Research focused on the effectiveness of the work of MCT largely confirms the findings of the research of the teams varying in terms of other features. Among the main benefits of multicultural teams' work, the ability to use different cognitive perspectives, resources, information and past experience in tasks requiring creative, innovative, out-of-the-box thinking which extends beyond the previous ways of solving problems, is particularly emphasized [Tadmor, C.T. et al. 2012, pp. 384-392; Crotty S.K. and Brett J.M., 2012, pp.210-234; Knippenberg D., Ginkel W.P. and Homan A.C, 2013, pp.183-193]. Additionally, the possibility of reducing the tendency towards groupthink with a simultaneous increase in learning opportunities is pointed out [Stahl G.K. et al. 2010, pp. 439-447]. What is more, the findings indicate a strong sense of job satisfaction in teams of this kind [Tirmizi S.A., 2008, p.3, Stahl G.K. et al. 2010, pp.439-447]. It is clearly emphasized, however, that the sources of advantages generate also the greatest threats to MCT, which leads to "process" type losses. These losses are due to inappropriate and ineffective communication and the presence of different patterns of behaviour that lead to interpersonal tensions, conflicts and intergroup biases [Spencer-Rodgers J. and McGovern T., 2002, pp. 609-631; Knippenberg D. et al., 2013, pp.183-193]. In this context, attention is 
drawn both to the type of task [Nouri R. et al., 2013] and to the team members' experience in working in MCT or the duration of work in a given, specific group, contributing to mutual understanding [Cheng Ch.Y. et al., 2012, pp.389-411; Popov V. et al., 2012, pp.302-317]. However, one of the factors having a significant impact on the efficiency of an intercultural team are attitudes and beliefs sometimes referred to as diversity mindset [Knippenberg D. et al. 2013, pp.183-193]. Especially important in relation to MCT operating within an organization is the fact that such attitudes can be shaped not only by individual experiences, but also in education and professional training [Spencer-Rodgers J. and McGovern T., 2002, pp. 609631; Cushner K., 2008, pp.164-173; Boski P., 2010, pp.566-610]. It is noted that individual (also professional) contacts with representatives of different cultures are not sufficient to make lasting changes in attitudes and beliefs. In contrast, frequent opportunities for cooperation on common tasks during an extended period (about 6-10 months) bring positive results [Williams Ch.T. and Johnson L.R., 2011, pp. 41-48; Behrnd V. and Porzelt S., 2012, pp. 213-223; Krawczyk - Brylka B. and Stankiewicz K., 2014, pp.19-30].

The group of individuals having such experiences includes students who have the opportunity to meet and cooperate within teams of people from different cultures. Their beliefs related to cross-cultural teams and the development of such attitudes during their studies can strongly influence their decisions and behaviour in the workplace. Therefore, it seems desirable to conduct research on this group's preferences related to work in SCT and MCT and the determinants of these preferences, which include the requirements of a task entrusted to a team. In order to verify this issue and check how the experience of working in SCT and MCT is related to preferences regarding work in any of these types of teams, a study described below was conducted.

\section{Present research}

The aim of the study was:

- to examine the preferences related to work in MCT vs. SCT among students preparing to work in the roles of managers and entrepreneurs in today's globalized labour market;

- to investigate whether preferences for working in MCT vs. SCT depend on the requirements of the task entrusted to the team;

- to verify whether such preferences are related to one's past experience in teamwork, including MCT and SCT.

Obtaining answers to research questions would allow for a preliminary assessment of the attitudes of the students surveyed, followed by selection of appropriate methods and means used in the course of further education.

The questionnaire survey covered 87 (51 women, 36 men) full-time students of International Management at the Faculty of Management and Economics of 
Gdańsk University of Technology. It is a programme during which both Polish and foreign students cooperate in intercultural teams on projects implemented according to the curriculum. The survey was conducted in May 2015 — at the end of a year of common classes. Table 1 shows the number of research participants according to their country of origin. The numbers of individuals coming from different countries are too small to make comparisons between countries. It is also not a purpose of the present study. The authors decided to place emphasis on the perception of the different aspects of teamwork by young people who have chosen to study among people from different cultures. The experiences and opinions of those individuals on the effectiveness of MCT may indeed prove crucial for their decisions on cooperation in teams in professional life.

Table 1 Number of research participants according to their country of origin

\begin{tabular}{|c|c|c|c|c|c|c|c|c|c|c|}
\hline Country of origin & $\begin{array}{l}\vec{E} \\
\frac{\vec{J}}{0} \\
0\end{array}$ & 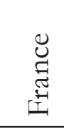 & $\begin{array}{l}\text { ज्ञ } \\
\text { مू }\end{array}$ & 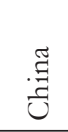 & 窵 & $\begin{array}{l}\overrightarrow{\vec{E}} \\
\vec{G} \\
\vec{I}\end{array}$ & 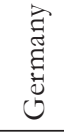 & 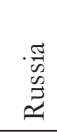 & 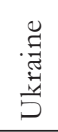 & 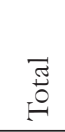 \\
\hline $\begin{array}{l}\text { Number of the study } \\
\text { participants }\end{array}$ & 64 & 8 & 4 & 4 & 3 & 1 & 1 & 1 & 1 & 87 \\
\hline
\end{tabular}

Source: own work.

\section{The method and research results}

In order to obtain answers to the first and second research question regarding preferences to work in SCT or MCT depending on the requirements of the task, the subjects were asked to answer the following question: "Imagine a situation in which you can choose to work either in a single-culture or a multicultural team. Which of those (single-culture or multicultural team) would provide greater possibility of success in face of each of the task requirements stated in the table below." The rest of the question consisted of a list of 19 requirements associated with a task based on previous literature review. These requirements were related to e.g. cognitive and informational diversity, flexibility, cooperation and commitment to the work of the team, as well as trust and atmosphere within the team. The respondents answered using a five-point Likert scale where 1 meant "I strongly agree that a single-culture team would provide higher chances of success, 2 „I agree that a single-culture team would provide higher chances of success', 3 "Neither a single or a multicultural team would provide higher chances of success", 4 "I agree that a multicultural team would provide higher chances of success", 5 "I strongly agree that a multicultural team would provide higher chances of success". 
The responses received were analysed statistically using the t-Student test for one group verifying the hypothesis of the presence vs. absence of responses indicating preferences related to working in one of the types of teams. Obtaining a mean of 3 for a given task requirement meant no preferences for working in SCT or MCT. Obtaining a mean of more than 3 indicated preference for MCT, while less than 3 indicated preference for teams consisting of members of one culture. The results obtained for the individual task requirements are presented in Table 2.

Table $2 \mathrm{t}$-Student test results showing the differences between the statements of the subjects and the tested value of 3 as a measure of their preference to work in SCT or MCT depending on the requirements of the job.

\begin{tabular}{|l|l|l|l|l|}
\hline & & & & \\
& & &
\end{tabular}

Source: own work.

The analysis of the results revealed that the surveyed students prefer to work in MCT most if the task requirements relate to creativity $(4,45)$, out-of-the-box thinking $(4,34)$ and resourcefulness $(3,81)$, i.e. when the requirements are related to availing of cognitive and informational diversity of the team members. This type of diversification may also include task requirements related to the ability to anticipate the future course of action. It should be noted however, that the preference for 
working in MCT in the latter case is weaker, but still statistically significant. A clear preference for working in MCT is also present if the task requires risk-taking (3.76) and commitment (3.37). The relatively weakest, but still statistically significant preference for working in MCT occurs when a task requires team climate (3.29) and cooperation (3.29). It is worth noting that these preferences relate to cognitive and informational diversity and are consistent with conclusions of research presented in the literature. The results related to the weak but statistically significant preference for working in $\mathrm{MCT}$ when the task requires not only cooperation but also team climate also seem quite interesting. Most literature reports indicate such tasks as challenging for this type of teams. The interpretation of the results obtained for this particular group of respondents can be influenced by its experience acquired during several months of attending the same classes.

Preferences to work in SCT are strongest when a task requires mutual understanding among team members (1.98) and like-mindedness (2.16). Clear preference for working in this type of team is also present when the task requires trust (2.2) and quick decision-making (2.33). The results seem to be logical and indirectly confirm the earlier answers regarding preference for working in SCT and MCT. It should be noted that the literature highlights both the advantages and the risks arising from the cognitive diversity characteristic for MCT. So if the task requires mutual understanding and like-mindedness, SCT appear to be more effective as unanimity stimulates the sense of trust and increases the chances for a quick decision.

In the light of previous findings lack of preference to work in SCT or MCT in a situation where the task requires e.g. flexibility is rather surprising. It seems that this requirement could be fulfilled while working in a MCT. It is worth noting, however, that the absence of preferences to work in SCT or MCT in the results obtained may mean that the task with such requirements is, in the opinion of the respondents, carried out equally effectively by each of these teams.

The objective of the next phase of the analysis was to determine whether work experience in SCT or MCT is associated with a preference to choose a particular type of team according to the requirements of the task to be performed. The subjects were asked to identify their level of experience of working in teams of both types in view of the following two statements on a seven-point Likert scale:

a. Indicate your level of experience in working in a single-culture team using a scale from 1 (no experience at all) to 7 (a lot of experience)

b. Indicate your level of experience in working in a multicultural team using a scale from 1 (no experience at all) to 7 (a lot of experience)

The statistical analysis of the results showed that the respondents reported a higher level of experience of working in SCT $(\mathrm{M}=5.76, \mathrm{SD}=1.39)$ than in MCT $(\mathrm{M}=4.48, \mathrm{SD}=1.69)$. At the same time, it is worth noting that the respondents 
reported that their experience of working in MCT is higher than average (the mean score above 4). In addition, it was also verified whether there are differences in the experience in the work in SCT and MCT between the Polish and the foreign students. Table 3 shows the descriptive statistics for each of the analysed groups.

Table 3. Descriptive statistics for the declared experience in work in SCT and MCT

\begin{tabular}{|l|l|l|l|l|}
\hline \multirow{2}{*}{} & \multicolumn{2}{|l|}{$\begin{array}{l}\text { Polish students } \\
(\mathrm{n}=64)\end{array}$} & $\begin{array}{l}\text { Foreign students } \\
(\mathrm{n}=23)\end{array}$ \\
\cline { 2 - 5 } & Mean & SD & Mean & SD \\
\hline Experience in working in SCT & 5.84 & 1.56 & 5.61 & 1.33 \\
\hline Experience in working in MCT & 4.35 & 1.73 & 4.78 & 1.56 \\
\hline
\end{tabular}

Source: own work.

Due to differences in the size of both groups, in order to verify the hypothesis of absence or existence of any differences in the experience of work in SCT and MCT between the Polish and foreign students, the U Mann-Whitney test, a nonparametric alternative for the t-Student test, was used. The test results showed absence of statistically significant differences between the Polish and foreign subjects, both in relation to the experience of working in SCT $(\mathrm{U}=935,5 ; \mathrm{p}$ nonsignificant) and MCT (U $=622$, p nonsignificant).

In order to obtain the answer to the question whether work experience in SCT or MCT is associated with a preference for a particular type of team depending on the requirements of the task, a Pearson's correlation analysis was conducted for each of the analysed variables. The results of statistically significant correlations are shown in Table 4. According to the method of construction of the research scale, negative correlation coefficients indicate a preference for work in SCT in the context of specific task requirements, whereas the positive ones indicate that MCT are preferred.

Table 4 Coefficients of statistically significant correlations between the experience of working in SCT and MCT and the preference for selecting a particular type of team depending on the requirements of a task

\begin{tabular}{|l|l|l|l|}
\hline Task requirement & r-Pearson & $\begin{array}{l}\text { Significance } \\
\text { level }\end{array}$ & $\begin{array}{l}\text { Preferences to } \\
\text { work in a team }\end{array}$ \\
\hline Team climate & 0.40 & 0.01 & MCT \\
\hline Self-confidence & 0.25 & 0.05 & MCT \\
\hline Creativity & 0.23 & 0.05 & MCT \\
\hline Trust & 0.23 & 0.05 & MCT \\
\hline Persistence & -0.22 & 0.05 & SCT \\
\hline Assuming responsibility by team members & -0.24 & 0.05 & SCT \\
\hline Trust & -0.27 & 0.05 & SCT \\
\hline Cooperation & -0.30 & 0.01 & SCT \\
\hline
\end{tabular}

Source: own work. 
The analysis of the results shows that the greater the declared experience of respondents in work in MCT, the more they prefer to work in such teams if the task requires team climate $(0.4)$, self-confidence $(0.25)$, creativity $(0.23)$ and trust $(0.23)$. In addition, the greater the declared experience of the respondents in working in SCT, the more they prefer to work in such teams if the task requires cooperation $(-0.3)$, trust $(-0.27)$, assuming responsibility by team members $(-0.24)$ or persistence $(-0.22)$.

The results seem to be very interesting and somewhat surprising. While interpreting the results of correlation one should be aware of the impossibility of determining the cause and effect relationship between variables. On the other hand, these results can be interpreted in the light of relationships mentioned in the previous part of the work. They indicate a high level of satisfaction with work in MCT [Tirmizi S.A., 2008, p.3; Pitts D., 2009, pp. 328-338], which may be associated with team climate, as well as point to reduction of the negative phenomenon of groupthink, which requires confidence of the team members [Stahl G.K. et al. 2010, pp.439-447]. The results obtained in the present study are an extension of previous results and link them with the requirements of the job and the experience of working in MCT.

A result worth emphasizing is the positive relationship between the level of experience in work of each of the types of teams and the mutual trust required to undertake a task. It is also worth noting that the experience of working in teams of one of the types was not negatively related to preferences for working in such teams within the context of any of the tested task requirements.

\section{Summary}

The study revealed that in the analysed group of students a generally understood diversity of cognitive perspectives was the most relevant factor related to preference to work in SCT or MCT. The respondents preferred to work in MCT if the task required diversity of cognitive perspectives, e.g. in a situation requiring creative or out-of-the-box thinking. In contrast, the strongest preference for working in SCT was present in the case of tasks requiring mutual understanding among the team members and like-mindedness. In addition, it was found that the preference to work in SCT or MCT entrusted with a task with specific requirements was also related to the experience in working in such teams declared by the respondents.

The study leads to conclusions of theoretical and practical nature. First of all, it is worth to note the optimistic, from the point of view of promoting diversity and preparing young people to take up professional work, conclusions that show that they appreciate the value of cross-cultural work in the implementation of certain tasks. This value is understood in the present article as a preference to work resulting from the conviction that such teams are more effective. Moreover, experience of 
working in such a team is not associated with negative beliefs about its capabilities. These results indicate the need to maintain the activities in which the future participants of the global labour market can collaborate in diverse teams already during their university studies. An important issue that in the authors' opinion requires further action is providing not only the very possibility of cooperation in cross-cultural teams, but also a deeper reflection on its possibilities and limitations. Such reflection could serve the conscious acquisition of cross-cultural competences and the ability to cope with difficult situations that occur when working in such teams. Such interactions could therefore be complemented by a range of additional activities such as intercultural training or coaching sessions aimed at helping the young people to understand the processes occurring during their work.

The study described in the present article also has its limitations, characteristic for surveys. A further valuable activity will be checking the actual choices made in such situations under controlled conditions. It is also important to verify the direction of the relationship between experience and preferences related to certain requirements of the performed tasks.

\section{References}

Bassett-Jones, N. (2005) 'The Paradox of Diversity Management, Creativity and Innovation' Creativity and Innovation Management, vol. 14, no. 2, pp. 169-175.

Behrnd, V. and Porzelt, S. (2012) 'Intercultural competence and training outcomes of students with experiences abroad', International Journal of Intercultural relations, vol. 36, no.2, pp. 213-223.

Bell M.P. and Berry D. P. (2007) 'Viewing Diversity Through Different Lenses: Avoiding a Few Blind Spots' Academy of Management Perspectives. vol. 21, no. 4, pp.21-25.

Boski, P. (2010) Kulturowe Ramy Zachowań Społecznych. Podręcznik Psychologii Międzykulturowej. Warszawa: Wydawnictwo Naukowe PWN.

Cheng, Ch. Y., Chua, R.Y.J., Morris, M.W. and Lee L. (2012) 'Finding the right mix: How the composition of self-managing multicultural teams' cultural value orientation influences performance over time' Journal of Organizational Behavior, vol. 33, pp. 389-411.

Church, A.H. (1998) 'From both sides now: the power of teamwork- fact or fiction?' Team Performance Management, vol. 4, no.2,pp. 42-52.

Crotty, S.K. and Brett, J.M. (2012) 'Fusing Creativity: Cultural Metacognition and Teamwork in Multicultural Teams', Negotiation and Conflict Management Research, vol 5, no. 2, pp. 210-234.

Cushner, K. (2008) 'International Socialization of Young People: Obstacles and Opportunities', International Journal of Intercultural Relations, vol. 32, No. 2, pp. 164-173.

Katzenbach, J.R. and Smith, D.K. (2001) Siła Zespołów. Wpływ pracy zespołowej na efektywność organizacji. Kraków: Oficyna Ekonomiczna.

Kellough, J.E. and Naff, K.C. (2004) 'Responding to Wake-Up Call: An Examination of 
Federal Agency Diversity Management Programs’ Administration \& Society. vol. 36, no. 1. pp. 62-90.

Knippenberg, D., Ginkel,W.P. and Homan, A.C. (2013) 'Diversity mindsets and the performance of diverse teams', Organizational Behavior \& Human Decision Processes, vol. 121, no. 2, pp. 183-193

Krawczyk-Bryłka B. and Stankiewicz K. (2014) 'Developing competences for cooperation in international teams - tools and methods' in Zięba, M and Zięba, K. (ed) Innovative approaches to business education. Selected issues. Horsens: VIA University College.

Lawthom, R. (2003) 'Przeciw wszelkiej nierówności: zarządzanie różnorodnością' in Chmiel, N. (ed.) Psychologia pracy i organizacji. Gdańsk: GWP.

Mannix, E. and Neale, M.A. (2005) 'What Difference Make a Dofference? The promise and Reality of Diverse Teams in Organizations', Psychological Science in the Public Interest, vol. 6, no. 2, pp 31-55.

Nouri,R., Erez,M., Rockstuhl, T., Ang, S., Leshem Calif, L., and Rafaeli, A. (2013) 'Taking the bite out of culture: The impact of task structure and task type on overcoming impediments to cross cultural team performance' Journal of Organizational Behavior, vol. 34, pp. 739-763.

Pillay, S. and James, R (2013) 'Gaming across cultures: experimenting with alternate pedagogies’, Education + Training, vol. 55, no.1, p.7-22.

Pitts, D. (2009) 'Diversity Management, Job Satisfaction, and Performance: Evidence from U.S. Federal Agencies’ Public Administration Review. vol. 69, no. 2, pp. 328-338.

Popov, V., Brinkman, B., Biemans, H.J.A., Mulder, M., Kuznetsov, A.M. and Noroozi, O. (2012) 'Multicultural student group work in higher education An explorative case study on challenges as perceived by students', International Journal of Intercultural relations, Vol 32. No.2, pp.302-317.

Roberge M.E. and Dick R. (2010) 'Recognizing the benefits of diversity: when and how does diversity increase group performance?’ Human Resource Management Review. vol. 20, pp. 295-308.

Shen, J., Chanda, A., D’Netto, B., and Monga, M. (2009) 'Managing diversity through human resource management: an international perspective and conceptual framework', The International Journal of Human Resource Management, vol. 20, no. 2, pp. 235-251.

Shore, L.M., Chung-Herrera, B.G., Dean, M.A., Holcombe Ehrhart, K., Jung, D.I., Randel, A. and Singh, G. (2009) 'Diversity in organizations: Where are we now and where are we going?’, Human Resource Management Review, vol. 19, no. 2, pp.117-133.

Spencer-Rodgers, J. and McGovern, T. (2002) 'Attitudes toward the culturally different: The role of intercultural communication barriers, affective responses, consensual stereotypes, and perceived threat'. International Journal of Intercultural Relations, vol. 26, no. 6, pp. 609-631.

Stahl,G.K., Mäkelä,K., Zander,L. and Maznewski, M.L. (2010) 'A look at the bright side of multicultural team diversity', Scandinavian Journal of Management, vol. 26, no. 4, pp. 439-447 
Tadmor, C.T., Satterstrom, P., Jang, S. and Polzer, J.T. (2012) 'Beyond Individual Creativity: The Superadditive Benefits of Multicultural Experience for Collective Creativity in Culturally Diverse Teams'. Journal of Cross-Cultural Psychology, vol. 43, no. 3, pp. 384392.

Tirmizi, S.A. (2008) 'Towards Understanding Multicultural Teams', in Halverson C.B and Tirmizi S.A.(ed.) Effective Multicultural Teams: Theory and Practice. Springer.

Unsworth K.L. and West M.A. (2003) 'Zespoły: wyzwania pracy w grupie', in Chmiel, N. (ed.) Psychologia pracy i organizacji. Gdańsk: GWP.

Williams, Ch.T. and Johnson, L.R. (2011) 'Why can't we be friends?: Multicultural attitudes and friendships with international students', International Journal of Intercultural Relations, vol. 35, pp. 41-48

Woehr D J, Arciniega L.M and Poling T.L (2013) 'Exploring the effects of value diversity on team effectiveness', Journal of Business \& Psychology, vol. 28, pp. 107-121

Electronic sources

Davies, A., Fidler, D. and Gorbis, M. (2011) Future Work Skills 2020, [Online] Available: http://www.iftf.org/uploads/media/SR-1382A_UPRI_future_work_skills_sm.pdf [29. May.2015] 